\title{
5 Research Square

\section{Exploring Bimetallic Au-Ag Core Shell Nanoparticles Reduced Using Leaf Extract of Ocimum Tenuiflorum as A Potential Antibacterial and Nanocatalytic Agent}

sneha nayak ( $\square$ snehanayak@nitte.edu.in )

NMAM Institute of Technology https://orcid.org/0000-0002-3751-0464

Chandrayan Vaman Rao

NMAM Institute of Technology

Srinivas Muttalik

Manipal College of Pharmaceutical Sciences

\section{Research Article}

Keywords: Biosynthesis, bimetallic nanoparticles, core-shell, OTAuAgNPs, Brilliant blue R250, adsorption kinetics, toxicity

Posted Date: January 21st, 2022

DOI: https://doi.org/10.21203/rs.3.rs-1175999/v1

License: (c) (i) This work is licensed under a Creative Commons Attribution 4.0 International License. Read Full License 


\section{Abstract}

Biosynthesis of bimetallic Au-Ag core shell nanoparticle under ambient condition using Ocimum tenuiflorum (Krishna Tulsi) leaf extract is being reported for the first time. For the biosynthesized bimetallic core shell nanoparticles (OTAuAgNPs) visual and spectrophotometric analysis was performed. Development of a deep purple color suggested the creation of OTAuAgNPs. It was then validated by UVVis spectrophotometry within 4 hours of incubation showing a surface plasmon resonance peak at 560 $\mathrm{nm}$. FESEM-EDAX, FT-IR, particle analyzer and XRD were the analytical techniques employed to characterize the biosynthesized OTAuAgNPs. Using a known antibiotic as a control, OTAuAgNPs had a substantial bacteriostatic effect against Gram +ve (Bacillus subtilis) and Gram -ve (E.coli, Pseudomonas aeruginosa) bacteria. The OTAuAgNPs showed good catalytic action for the adsorption of Coomassie brilliant blue R250 dye (CBB), confirmed by the reduction in absorbance maxima that is time dependant. A remarkable adsorption of CBB (94.79\%) was attained within $120 \mathrm{~min}$, and the results were best suited PSO and Elovich models with adsorption kinetic constant of $5.96 \mathrm{E}^{-04} \mathrm{~g} / \mathrm{mg} \cdot \mathrm{min}$ and $37.81 \mathrm{mg} / \mathrm{g} . \mathrm{min}$ respectively. Further the toxicity studies of brilliant blue R250 dye and metabolite of CBB (post nanoremediated dye solution) was carried out on Vigna radiata (green gram) germination and growth. OTAuAgNPs as nano catalyst remediated water revealed that it was nontoxic. Thus an ecofriendly and cost effective approach for bimetallic nanoparticle synthesis could be further explored for removal of CBB from wastewater effluents.

\section{Introduction}

The use of biological agents to synthesize bimetallic nanoparticles (NPs) has gained popularity due to its cost-effectiveness, environmental friendliness, and ease of scaling up without utilization of lot of energy and use of harmful chemicals (Khan et al., 2020; Padilla-Cruz et al., 2021). Plant extract-based NP biosynthesis is more stable and has a higher rate of synthesis than other biological processes. It also doesn't require cell culture care and can be stepped up for large-scale synthesis (Gour et al., 2019). Researchers have recently begun concentrating on the production of bimetallic nanoparticles in order to investigate the potential of two metals for a variety of applications (Sharma et al., 2019). Furthermore, there are only a few recent studies on biological synthesis core and shell bimetallic nanoparticles, from aqueous plant extracts; to name a few $\mathrm{Ag}$-Fe nanoparticles synthesized using Gardenia jasminoides leaf extract (Padilla-Cruz et al., 2021), silver-platinum nanoparticles biogenically synthesized using Schinusmolle L. leaf extract (Mares-Briones et al., 2019) and Au-Ag nanoparticles synthesized using weed Antigonon leptopus which is of no value (Ganaie et al.,2016).

The dye industry's wastewater is the second most dangerous industrial effluent, with around 100 tonnes of dye released each year (Benkhaya et al., 2020). Because of their synthetic origins and intricate structures, dye discoloration is difficult (Mozzoli et al., 2021). Nanoparticles are increasingly being used to treat dye effluents due to their qualities such as greater nano-adsorptive capabilities, faster attainment of equilibrium, and large surface area (Homaeigohar et al., 2020). Adsorption, photocatalytic degradation, and adsorption plus degradation are all mechanisms for hazardous dye elimination by nanoparticles 
(Alkaykh et al., 2020). Textile effluents are known to have detrimental effects on plants by bioaccumulation/disrupting photosynthesis mechanism in aquatic flora (plants and algae) (Berradi et al., 2019). Since degradative products of dyes can sometimes be much more mutagenic and carcinogenic than the parent compounds, understanding the toxicity of nano-remediated water on plant growth is important (Lellis et al., 2019). Keeping this in view, the study was undertaken to see the effect of dye and nano-remediated dye solution on germination and growth of Vigna radiata.

The current study, thus, focuses on biological plant based synthesis of bimetallic Au-Ag nanoparticles from Ocimum tenuiflorum (Krishna tulsi) leaf extract (OTAuAgNPs). Holy basil, or Ocimum tenuiflorum, is a plant native to the Indian subcontinent that is widely cultivated across the Southeast Asian tropics (Mousaviwt al., 2018). Although it is known to have potential health benefits such as antimicrobial (Yamani et al., 2016), anti-diabetic (Mousaviwt al., 2018), antioxidant and protection of DNA from damage (Sarkar et al.,2014), there are no reports on biosynthesis of bimetallic gold-silver nanoparticles using this plant for the applications of environmental remediation. Synthesized OTAuAgNPs were depicted by UV-Visible spectrophotometry, particle size and zeta sizer, Fourier Transform Infrared Spectroscopy (FT-IR) and X-Ray diffraction (XRD) analysis. This is the first report on CBB adsorption by bimetallic Au-AgNPs produced from Ocimum tenuiflorum, with focus on understanding the kinetics of adsorption and understanding the toxicity of the metabolite (nano-catalyst treated water) on Vigna radiata (green gram) germination and growth.

\section{Materials And Methods}

\subsection{Plant material and chemicals}

Fresh and firm Ocimum tenuiflorum leaves were got from Nitte $\left(13.1859^{\circ} \mathrm{N}, 74.9395^{\circ} \mathrm{E}\right)$ and Belman $\left(13.1664^{\circ} \mathrm{N}, 74.8712^{\circ} \mathrm{E}\right.$ ) premises (Fig. $\left.1 \mathrm{~A}\right) . \mathrm{AgNO}_{3}$ and $\mathrm{HAuCl}_{4}$ required for nanoparticles synthesis was procured from Loba Chemie. Unless otherwise stated, all other compounds and reagents employed in the current study were of analytical grade. Coomassie Brilliant blue R250 analytical grade were bought from Hi-Media (Mumbai, India).

\subsection{Ocimum tenuiflorum leaf extract preparation}

Freshly plucked leaves of Ocimum tenuiflorum (Krishna tulsi) got from the premises were washed thoroughly with tap water and distilled water. The finely chopped leaves suspended in distilled water at a ratio $1: 10$ were heated at $80^{\circ} \mathrm{C}$ with occasional swirling for $30 \mathrm{~min}$. Filtrate was then filtered and stored at refrigerator condition $\left(4^{\circ} \mathrm{C}\right)$ until further use.

\subsection{Synthesis of OTAuAgNPs}

OTAuAgNPs were synthesized by mixing Ocimum tenuiflorum leaf extract with silver nitrate and gold chloride solution $(1.0 \mathrm{mM})$ each such that $25 \mathrm{ml}$ of the ready leaf extract was added to $115 \mathrm{ml}$ of $1 \mathrm{mM}$ aq. $\mathrm{AgNO}_{3}$ and $110 \mathrm{ml}$ of $1 \mathrm{mM} \mathrm{HAuCl}_{4}$. This blend was incubated at $27 \pm 2^{\circ} \mathrm{C}, 100 \mathrm{RPM}$ agitation speed 
and observed for color change in the solution. The OTAuAgNP pellet was obtained by centrifuging the sample at 10,000 RPM for 30 minutes. The pellet was cleaned twice with sterile distilled water, dried in a desiccator, and reserved for future use.

\subsection{Characterization of OTAuAgNPs}

The colloidal solution of synthesized OTAuAgNPs was characterized by recording its absorbance between 200 nm - 670 nm using a UV-Vis spectrophotometer (Thermo-Merck, Germany). Dried OTAuAgNPs were subjected to gold sputtering and fixed on to aluminium stubs. In order to recognize the functional groups of Ocimum tenuiflorum on OTAuAgNPs, FT- IR (Perkin Elmer System 2000, England) was performed with potassium bromide between $4000 \mathrm{~cm}^{-1}$ to $400 \mathrm{~cm}^{-1}$. Their morphological characteristics and fundamental composition were determined by SEM-EDX (JEOLJSM-7800F) under different magnifications. X-ray diffraction (RigakuMiniflex600, Japan) is used for phase identification of crystalline OTAuAgNPs by finding out its diffraction angles. This method revealed the crystalline structure of nanoparticles.

\subsection{Application of OTAuAgNPs \\ 2.5.1 Bactericidal activity of OTAuAgNPs}

\subsubsection{Strains and media}

Lyophilized P. aeruginosa, E. coli (Gram - ve) and B. subtilis (Gram + ve) were obtained from MTCCChandigarh. Bacterial growth initiation was done by adding a pinch of lyophilized bacteria in YPD medium and growing for $24 \mathrm{hrs}$.

\subsubsection{Study of bactericidal activity of OTAuAgNPs}

Bactericidal activity of OTAuAgNPs against Gram + ve (B. subtilis) and Gram - ve (E. coli, P. aeruginosa) were investigated. For antimicrobial assay, fresh microbial colonies $(100 \mu l)$ were inoculated into $10 \mathrm{ml}$ of nutrient broth medium. After 16 to $18 \mathrm{hrs}$ of incubation the $\mathrm{cfu} / \mathrm{ml}$ was calculated for $1: 10^{5}$ dilutions which corresponds to $1.7 \times 10^{9}, 9.3 \times 10^{8}$ and $6.7 \times 10^{8} \mathrm{cfu} / \mathrm{ml}$ for $E$. coli, B. subtilis, P. aeruginosa respectively. OTAuAgNPs were reconstituted in DMSO at concentration $10 \mathrm{mg} / \mathrm{ml}$. Bactericidal activity of OTAuAgNPs against gram +ve and gram -ve microbes were carried out (Philip et al., 2011). DMSO, Ocimum tenuiflorum leaf extract, $1 \mathrm{mM}$ aqueous bimetallic solution $\left(\mathrm{AgNO}_{3}\right.$ and $\mathrm{HAuCl}_{4}$ ) and Ciprofloxacin $(10 \mathrm{mg} / \mathrm{ml})$ served as control. The inhibition zones were then measured as per standard protocol (Philip et al., 2011).

\subsubsection{Adsorption of CBB by OTAuAgNPs}

OTAuAgNPs $(6.5 \mathrm{mg})$ was incubated with aqueous solution of CBB $(50 \mathrm{mg} / \mathrm{L}, 25 \mathrm{~mL})$ at $27 \pm 2^{\circ} \mathrm{C}, 100 \mathrm{RPM}$. Residual concentration of CBB was measured by recording absorbance of aqueous solution at $552 \mathrm{~nm}$ ( $\lambda$ max) every $30 \mathrm{~min}$. \%Adsorption and amount of adsorbed dye were calculated as per equations 1 and 2 respectively. 


$$
\% \text { Adorption }=\frac{C o-C}{C o} * 100(1)
$$

Where $\mathrm{Co}$ and $\mathrm{Ct}$ are the initial and periodic CBB concentration respectively

$$
Q_{t}=\frac{v(C o-C)}{W}
$$

Where $Q t=$ Dye adsorbed $(\mathrm{mg} / \mathrm{g}), V$ is total volume (in liters) and $W$ is OTAuAgNPs mass $(\mathrm{g})$.

\subsubsection{Adsorption Kinetics}

The adsorption kinetics of CBB by OTAuAgNPs was studied by fitting experimental values to pseudo first order (PFO), pseudo second order (PSO), Elovich and intra-particular diffusion kinetic equations. It is often noted that adsorption kinetics is a function of adsorbate concentration (Kamath Miyar et al., 2021). The following equations 3 and 4 depict the PFO and PSO kinetics which were modeled to study the adsorption process of CBB by OTAuAgNPs.

$$
\log (Q e-Q t)=\log Q e-\frac{k}{2.303}(3)
$$

Where $Q e$ and $Q t=$ Adsorbed CBB $(\mathrm{mg} / \mathrm{g})$ at equilibrium and time respectively and $k\left(\mathrm{~min}^{-1}\right)$ is PFO rate constant

$$
\frac{t}{Q t}=\frac{1}{k^{\prime} Q e^{2}}+\frac{1}{Q e} t(4)
$$

Where $\mathrm{k}^{1}(\mathrm{~g} / \mathrm{mg} . \mathrm{h})$ is the PSO rate constant

Elovich model describes the adsorption process as chemisorption and is denoted by the following equation

$$
Q t=\frac{1}{\beta} \ln (\alpha \beta)+\frac{1}{\beta} \ln t(5)
$$


Where $\mathrm{a}=$ preliminary adsorption rate $(\mathrm{mg} / \mathrm{g} \mathrm{h})$ and $\beta$ is a constant dependent on activation energy (g/mg).

Intraparticular diffusion model is essential in determination of rate limiting step in the adsorption process and is described by equation 6 .

$$
Q t=K p \sqrt{t}+C(6)
$$

Where $k p$ is the intraparticular rate constant of diffusion $(\mathrm{mg} / \mathrm{g} \mathrm{h})$.

\subsubsection{Toxicity studies of CBB and post nano-remediated water on Vigna radiata}

CBB solution ( $50 \mathrm{mg} / \mathrm{L})$ and post nano-remediated water $(2.6 \mathrm{mg} / \mathrm{L})$ were used for phytotoxicity study. The phytotoxicity study was carried out (at room temperature) in relation to Vigna radiata (6 seeds each). The seeds were soaked overnight in respective solutions, next day, the seeds were covered with moist cloth and kept in warm place $\left(>30^{\circ} \mathrm{C}\right.$ and $\left.<37^{\circ} \mathrm{C}\right)$ for germination. After soaking the seeds in distilled water, the control set was also kept in the same manner. Each treatment's percent germination, plumule (shoot) length, and radicle (root) length were measured every 24 hours for about 5 days. For each batch, 6 seedlings were chosen to record morphological data such as shoot length and root length in $\mathrm{cm}$ scale. The tolerance index, percent germination, and percent phytotoxicity were also calculated.

$\%$ germination was calculated $=\frac{\text { Number of seeds germinated }}{\text { total number of seeds }} \times 100$

Chou et al 1978 proposed a formula for calculating the dye's and its metabolite's percent phytotoxicity

$$
\% \text { phytotoxicity }=\frac{\text { radiclelengthofcontrol }- \text { radiclelengthoftextseed }}{\text { radiclelengthofcontrol }} X 100
$$

\section{Results And Discussion}

\subsection{Characterization of OTAuAgNPs}

\subsubsection{UV-Visible spectrophotometry}

The synthesis of bimetallic OTAuAgNPs nanoparticles was evidenced by a variation in the color of the solution from light yellow to give deep purple (Fig. 1B). A single surface plasmon peak at $560 \mathrm{~nm}$ was 
confirmed by UV-Visible spectrophotometric reading which corresponds to gold shell (Loiseau et al., 2019). According to the literature, Au-Ag bimetallic core shell nanoparticles have a sole surface plasmon resonance peak that corresponds to the shell material, whereas Au-Ag alloy nanoparticles have two peaks (Borah et al.,2020). In the current study, single SPR was observed corresponding to bimettalic core shell nature of OTAuAgNPs (Fig. 1A).

\subsubsection{FTIR spectroscopy}

The FTIR peak at $3350 \mathrm{~cm}^{-1}$ vanished in the bimetallic core shell nanoparticles made from Ocimum tenuiflorum extract, despite the fact that the peak could be found in the extract, indicating that phenolic groups are involved in nanoparticle reduction (Kulkarni et al., 2013). The presence of proteins in the extract implicated in the creation of nanoparticles is confirmed by FTIR data, which showed increased intensity of the peak at $2360 \mathrm{~cm}^{-1}$ (Nayak et al., 2020). FTIR analysis showed $3736 \mathrm{~cm}^{-1}$ as the maximum spike at which it matches to the frequency of $\mathrm{OH}$-bonds stretching coming from carbohydrates or proteins in the sample, confirming that proteins were present in both the extract (Fig. 2) and the nanoparticles (Fig. 3) (Vincent et al.,2020).

\subsubsection{SEM-EDX for analysis of morphology and composition of OTAuAgNPs}

SEM-EDX is a powerful tool for depiction of spatial resolution and composition of nanoparticles. On visualization of synthesized bimetallic OTAuAgNPs under SEM under various resolutions, a clear image of uniformly shaped spheres of sizes 20-30 nm (Fig. 4a). EDX analysis discovered the existence of characteristic sharp gold and silver peaks at around $2 \mathrm{keV}$ and $3 \mathrm{keV}$ confirming the formation of bimetallic OTAuAgNPs (Fig. 4b).

\subsubsection{Size distribution and zeta potential}

Figure 5 shows the size distribution by intensity of bimetallic nanoparticles with size of $202 \mathrm{~nm}$ and intensity of $100 \%$ having Z-avg of $179.9 \mathrm{~nm}$ and low polydispersity index (PDI) of 0.129 and negative Zeta potential value of $24.8 \mathrm{mV}$ of OTAuAgNPs. This suggests that the molecules coated over OTAuAgNPs are primarily made up of negative charge groups and are also accountable for the nanoparticles' modest stability. The negative zeta potential values of Au-Ag bimetallic nanoparticles formed using Pulicaria undulata extract correspond to negatively charged plant phytochemicals capping the nanoparticles (Khan et al.,2020). Zeta potential values in the range of $-9 \mathrm{mV}$ to $-19 \mathrm{mV}$ were obtained, which are quite similar to the results described by Khan et al., 2020.

\subsubsection{XRD studies}

The OTAuAgNPs XRD patterns were recorded (Fig. 6). The pattern of OTAuAgNPs revealed four distinct diffraction peaks in the 2 range, corresponding to the (111), (200), (220), and (311) planes, at 37.85, 43.87, 64.27, and $76.95^{\circ}$ by JCPDS: 4-0783 and 4-0784 (Yallappa et al.,2015). Same kind of peaks were specified by Yallappa et al., 2015 for Au-Ag core shell nanoparticles biologically produced using Rumex hymenosepalus root extract. Furthermore, using the Scherrer equation, the average crystal sizes of 
OTAuAgNPs were computed as $21.4 \mathrm{~nm}$. The obtained XRD figure clearly demonstrated that, bimetallic core shell nanoparticles are generated by the reduction in $\mathrm{Ag}^{+}$and $\mathrm{AuCl}_{4}$ ions by the phytochemicals of Ocimum tenuiflorum leaf extracts. The bimetallic nanoparticles were crystalline in nature. Several extra and unnamed peaks were observed near the bimetallic nanoparticles' unique peaks, in addition to the normal peaks. These peaks could be attributable to the extract's bioorganic components or proteins (Nayak et al., 2019).

\subsection{Antibacterial activity of OTAuAgNPs}

As demonstrated in figure 7, biologically produced OTAuAgNPs had anti-bacterial action opposite Gram ve (Pseudomonas aeruginosa and E.coli) and Gram +ve (Bacillus subtilis) bacteria. The zone of inhibition was defined as the bright zones surrounding the wells. The anti-bacterial activity of OTAuAgNPs against Gram +ve (Bacillus subtilis) bacteria and was much higher than that of Gram -ve (Pseudomonas aeruginosa and E.coli) bacteria possibly due to the negatively charged nanoparticle surface. It is a known fact that nanoparticles surface charge has a significant impact on its bactericidal activity against various test organisms (Abbaszadegan et al., 2015).

\subsection{Adsorption of CBB by OTAuAgNPs}

The adsorptive ability of synthesized OTAuAgNPs was studied by addition of UL-NPs $(6.5 \mathrm{mg})$ to an aqueous solution of CBB ( $50 \mathrm{mg} / \mathrm{L})$. The adsorption increased rapidly till $2 \mathrm{~h}$ after which the process slowed down (Fig. 8). Maximum adsorption \% of $94.79 \pm 0.12 \%$ was achieved in $2 \mathrm{~h}$ of incubation while residual concentration of CBB in the solution was $2.605 \pm 0.11 \mathrm{mg} / \mathrm{L}$. For CBB, the highest adsorption capacity was found as $183 \mathrm{mg} / \mathrm{g}$. Microwave synthesized hydroxyapatite nanoparticles had a highest adsorption capacity of $14.51 \mathrm{mg} / \mathrm{g}$ (Wang et al., 2019). Results reveal that OTAuAgNPs can be effectively used for remediation of CBB by dye adsorption mechanism.

\subsubsection{Adsorption Kinetics}

Adsorption kinetic studies is an important in the design of adsorption processes because it helps to understand the adsorption mechanism and estimate diffusion. PFO, Elovich, PSO, and intraparticular models of diffusion were used to investigate the adsorption kinetics of CBB by OTAuAgNPs (Fig. 8). PSO model well described the adsorption of CBB by OTAuAgNPs $\left(R^{2}=0.9839\right)$ and also predicted the equilibrium adsorption capacity $(181 \mathrm{mg} / \mathrm{L})$ close to the experimental value $(183.3 \mathrm{mg} / \mathrm{L})$. This shows that, degree of CBB adsorption by OTAuAgNPs is proportionate to the CBB concentration and follows the PSO and Elovich model, confirming the chemisorption of dyes on nanoparticle surfaces. Adsorption of methyl orange by UiO-66- $\mathrm{NO}_{2}$ nanoparticles also fitted PSO and Elovich model which confirmed the chemisorption interaction among the dye and the nanoparticle surface (Dinh et al.,2021). The rate constant of the process was observed as $5.96 \mathrm{E}^{-04} \mathrm{~g} / \mathrm{mg}$.min. The intraparticular diffusion plot revealed that CBB adsorption rate by OTAuAgNPs was initially controlled by intraparticular diffusion (upto45 min) after which it was governed by multiple steps. This was indicated by the multilinear nature of the plot 
(Fig. 9d). Further, the kinetic parameters based on the studies of adsorption of CBB on OTAuAgNPs are shown in (Table 1).

Table 1 Kineticparametersofadsorption ofCBB on OTAuAgNPs

\begin{tabular}{|ll|}
\hline Parameters & CBB $(\mathrm{mg} / \mathrm{L})$ \\
\cline { 2 - 2 } & $\mathbf{5 0}$ \\
\hline Qe,exp $(\mathrm{mg} / \mathrm{g})$ & 183.3 \\
\hline$P F O$ & \\
\hline$k\left(\mathrm{~min}^{-1}\right)$ & 0.026 \\
\hline$Q e, \mathrm{cal}(\mathrm{mg} / \mathrm{g})$ & 140.24 \\
\hline$R^{2}$ & 0.9726 \\
\hline$P S O$ & \\
\hline$k^{\prime}(\mathrm{g} / \mathrm{mg} \cdot \mathrm{min})$ & $\mathbf{5 . 9 6 \mathrm { E } - 0 4}$ \\
\hline$Q e, \mathrm{cal}(\mathrm{mg} / \mathrm{g})$ & $\mathbf{1 8 1 . 8 1}$ \\
\hline$R^{2}$ & 0.9839 \\
\hline Elovich & \\
\hline$a(\mathrm{mg} / \mathrm{g} \cdot \mathrm{min})$ & 37.81 \\
\hline$\beta(\mathrm{g} / \mathrm{mg})$ & 0.0265 \\
\hline$R^{2}$ & 0.9983 \\
\hline
\end{tabular}

\subsection{Toxicity studies of CBB and its metabolite on Vigna radiata}

Table 2 shows the effect of of brilliant blue (BB) and its metabolite (MBB) on seed germination, radicle and plumule length, and phytotoxicity on Vigna radiata. Plants treated with CBB had an average length of $7.75 \mathrm{~cm}$, while those treated with its metabolite had an average length of $10.27 \mathrm{~cm}$, which was higher than the control samples (plant treated with water). Apparently, it is evident from the previous scientific studies that gold nanoparticles enhance the growth of seed yield in Brassica juncea (Arora et al., 2012). The effect of CBB, MCBB and control (water) on germination and seedling of Vigna radiata is shown in Fig. 10 and Fig. 11 respectively. It is also evident from literature that, colloidal solutions of metal nanoparticles have been used as a micronutrient fertilizer for cereals (Batsmanova et al., 2013). This might be the reason for better growth of plants which were treated with metabolite of CBB which was treated with 
OTAuAgNPs. Hence from this study it is evident that metabolite of CBB (nano-remediated dye solution) did not show toxicity on Vigna radiata germination nor growth.

Table 2

Effect of $\mathrm{CBB}$ and its metabolite (MCBB) on seed germination, radicle length, plumule length, phytotoxicity on Vigna radiata

\begin{tabular}{|c|c|c|c|c|c|c|c|}
\hline \multirow[t]{4}{*}{$\begin{array}{l}\text { Sample } \\
\text { code }\end{array}$} & \multirow[t]{4}{*}{$\begin{array}{l}\text { Number of seed } \\
\text { germinated }\end{array}$} & \multirow[t]{4}{*}{$\begin{array}{l}\% \\
\text { germination }\end{array}$} & \multicolumn{2}{|c|}{$\begin{array}{l}\text { Radicle } \\
\text { length } \\
\text { (cm ) after } \\
24 \text { hrs }\end{array}$} & \multicolumn{2}{|c|}{$\begin{array}{l}\text { Plumule length } \\
\text { (cm) after } \\
5 \text { days }\end{array}$} & $\begin{array}{l}\% \\
\text { Phytotoxicity }\end{array}$ \\
\hline & & & 2.2 & & 6.9 & & \\
\hline & & & 2 & & 5.1 & & \\
\hline & & & 2.9 & & 9.8 & & \\
\hline \multirow[t]{6}{*}{ BB } & 6 & 100 & 1.3 & 1.57 & 6.5 & 7.75 & 35.12 \\
\hline & & & 0.5 & & 9.7 & & \\
\hline & & & 0.5 & & 8.5 & & \\
\hline & & & 3 & & 6.4 & & \\
\hline & & & 2.6 & & 9 & & \\
\hline & & & 2.9 & & 12.3 & & \\
\hline \multirow[t]{5}{*}{ MCBB } & 6 & 100 & 2.7 & 2.81 & 11.7 & 10.27 & - \\
\hline & & & 2 & & 11.7 & & \\
\hline & & & 3.7 & & 10.5 & & \\
\hline & & & 2.8 & & 9.7 & & \\
\hline & & & 2.8 & & 12 & & \\
\hline \multirow[t]{4}{*}{ Control } & 6 & 100 & 2.3 & 2.42 & 10.3 & 8.62 & - \\
\hline & & & 2.8 & & 7.3 & & \\
\hline & & & 3.3 & & 8.7 & & \\
\hline & & & 0.5 & & 3.7 & & \\
\hline
\end{tabular}

\section{Conclusion}


In the design of processes utilizing innovative nano-adsorbents, determining adsorption kinetics and safety is critical. The current study reports for the very first time, the adsorption of CBB by bimetallic AuAg nanoparticles biologically produced using Ocimum tenuiflorum leaf extract which is also a potent bactericidal agent. The synthesized OTAuAgNPs had an SPR of $560 \mathrm{~nm}$, were capped by water soluble phytochemicals of Ocimum tenuiflorum leaf and were crystalline in nature. They could effectively adsorb residual concentration of CBB $(94.79 \pm 0.12 \%)$ owing to their large surface area. Toxicity studies on seed germination, radicle length, plumule length, phytotoxicity on Vigna radiata revealed that the metabolite of the dye produced by catalytic reduction using OTAuAgNPs is less toxic and improved the growth of plants due to micronutrient effect of metal nanoparticle. Thus the work presents an innovative, environment friendly and safe technique for treatment of wastewaters polluted with dyes using bimetallic Au-Ag nanoparticles.

\section{Declarations}

Ethics Approval: The study does not involve the use of humans or animals and hence does not require ethical approval.

Consent to Participate: All authors agree to participate in this investigation.

Consent for Publication: All authors agree to participate in this article.

Authors Contributions: All authors have read and approved the final manuscript. Sneha Nayak performed the research and wrote the paper. C Vaman Rao and Srinivas Muttalikhelped in analysis of data, and mentored during paper writing.

Funding: No funding have been received for this research work.

Conflict of Interest: None.

Research Involving Humans and Animals Statement: This manuscript does not contain research involving humans and animals.

Availability of data and materials: Not applicable, Supplementary material will be available on request.

\section{References}

1. Abbaszadegan A, Ghahramani Y, Gholami A, Hemmateenejad B, Dorostkar S, Nabavizadeh M, Sharghi $\mathrm{H}$. The effect of charge at the surface of silver nanoparticles on antimicrobial activity against gram-positive and gram-negative bacteria: a preliminary study. Journal of Nanomaterials. 2015 Oct;2015.

2. Alkaykh S, Mbarek A, Ali-Shattle EE. Photocatalytic degradation of methylene blue dye in aqueous solution by MnTiO3 nanoparticles under sunlight irradiation. Heliyon. 2020 Apr 1;6(4):e03663. 
3. Arora S, Sharma P, Kumar S, Nayan R, Khanna PK, Zaidi MG. Gold-nanoparticle induced enhancement in growth and seed yield of Brassica juncea. Plant growth regulation. 2012 Apr;66(3):303-10.

4. Batsmanova LM, Gonchar LM, Taran NY, Okanenko AA. Using a colloidal solution of metal nanoparticles as micronutrient fertiliser for cereals (Doctoral dissertation, Sumy State University).

5. Benkhaya S, M'rabet S, El Harfi A. A review on classifications, recent synthesis and applications of textile dyes. Inorganic Chemistry Communications. 2020 May 1;115:107891.

6. Berradi M, Hsissou R, Khudhair M, Assouag M, Cherkaoui O, El Bachiri A, El Harfi A. Textile finishing dyes and their impact on aquatic environs. Heliyon. 2019 Nov 1;5(11):e02711.

7. Borah R, Verbruggen SW. Silver-gold bimetallic alloy versus core-shell nanoparticles: Implications for plasmonic enhancement and photothermal applications. The Journal of Physical Chemistry C. 2020 May 7;124(22):12081-94.

8. Chou $\mathrm{CH}$, Chiang YC, Kao Cl. Impacts of water pollution on crop growth in Taiwan. II. Phytotoxic natures of six rivers and twenty seven industrial waste waters in Kaohsiung area, Taiwan. Bot. Bull. Acad. Sinica (Taiwan);(Taiwan). 1978 Jul 1;19(2).

9. Dinh HT, Tran NT, Trinh DX. Investigation into the Adsorption of Methylene Blue and Methyl Orange by UiO-66-NO2 Nanoparticles. Journal of Analytical Methods in Chemistry. 2021 Jun 14;2021.

10. Ganaie SU, Abbasi T, Abbasi SA. Rapid and green synthesis of bimetallic Au-Ag nanoparticles using an otherwise worthless weed Antigononleptopus. Journal of Experimental Nanoscience. $2016 \mathrm{Apr}$ 12;11(6):395-417.

11. Gour A, Jain NK. Advances in green synthesis of nanoparticles. Artificial cells, nanomedicine, and biotechnology. 2019 Dec 4;47(1):844-51.

12. Homaeigohar S. The nanosized dye adsorbents for water treatment. Nanomaterials. 2020 Feb;10(2):295.

13. Khan M, Al-Hamoud K, Liaqat Z, Shaik MR, Adil SF, Kuniyil M, Alkhathlan HZ, Al-Warthan A, Siddiqui MR, Mondeshki M, Tremel W. Synthesis of Au, Ag, and Au-Ag bimetallic nanoparticles using Pulicariaundulata extract and their catalytic activity for the reduction of 4-nitrophenol. Nanomaterials. 2020 Sep;10(9):1885.

14. Kulkarni VD, Kulkarni PS. Green synthesis of copper nanoparticles using Ocimum sanctum leaf extract. Int J Chem Stud. 2013;1(3):1-4.

15. Lellis B, Fávaro-Polonio CZ, Pamphile JA, Polonio JC. Effects of textile dyes on health and the environment and bioremediation potential of living organisms. Biotechnology Research and Innovation. 2019 Jul 1;3(2):275-90.

16. Loiseau A, Zhang L, Hu D, Salmain M, Mazouzi Y, Flack R, Liedberg B, Boujday S. Core-shell gold/silver nanoparticles for localized surface Plasmon resonance-based naked-eye toxin biosensing. ACS applied materials \& interfaces. 2019 Nov 20;11(50):46462-71.

17. Mares-Briones F, Barragán-Mares O, López-Miranda JL, Esparza R, Rosas G. Bimetallic Ag@ Pt coreshell nanoparticles and their catalytic activity by a green approach. Materials Research Express. 
2019 Jun 21;6(8):0850h8.

18. Mazzoli R, Pessione E. Ancient Textile Deterioration and Restoration: Bio-Cleaning of an Egyptian Shroud Held in the Torino Museum. Microorganisms in the Deterioration and Preservation of Cultural Heritage. 2021:199.

19. Miyar HK, Pai A, Goveas LC. Adsorption of Malachite Green by extracellular polymeric substance of Lysinibacillus sp. SS1: kinetics and isotherms. Heliyon. 2021 May 29:e07169.

20. Mousavi L, Salleh RM, Murugaiyah V. Phytochemical and bioactive compounds identification of Ocimumtenuiflorum leaves of methanol extract and its fraction with an anti-diabetic potential. International Journal of Food Properties. 2018 Jan 1;21(1):2390-9.

21. Nayak S, Sajankila SP, Goveas LC, Rao VC, Mutalik S, Shreya BA. Two fold increase in synthesis of gold nanoparticles assisted by proteins and phenolic compounds in Pongamia seed cake extract: response surface methodology approach. SN Applied Sciences. 2020 Apr;2(4):1-2.

22. Nayak S, Sajankila SP, Rao CV, Hegde AR, Mutalik S. Biogenic synthesis of silver nanoparticles using Jatrophacurcas seed cake extract and characterization: evaluation of its antibacterial activity. Energy Sources, Part A: Recovery, Utilization, and Environmental Effects. 2019 Jun 24:1-9.

23. Padilla-Cruz AL, Garza-Cervantes JA, Vasto-Anzaldo XG, García-Rivas G, León-Buitimea A, MoronesRamírez JR. Synthesis and design of ag-fe bimetallic nanoparticles as antimicrobial synergistic combination therapies against clinically relevant pathogens. Scientific Reports. 2021 Mar 5;11(1):10 .

24. Philip D, Unni C. Extracellular biosynthesis of gold and silver nanoparticles using Krishna tulsi (Ocimum sanctum) leaf. Physica E: Low-dimensional Systems and Nanostructures. 2011 May 1;43(7):1318-22.

25. Sarkar B, Kumar D, Sasmal D, Mukhopadhyay K. Antioxidant and DNA damage protective properties of anthocyanin-rich extracts from Hibiscus and Ocimum: a comparative study. Natural product research. 2014 Sep 2;28(17):1393-8.

26. Sharma G, Kumar A, Sharma S, Naushad M, Dwivedi RP, ALOthman ZA, Mola GT. Novel development of nanoparticles to bimetallic nanoparticles and their composites: a review. Journal of King Saud University-Science. 2019 Apr 1;31(2):257-69.

27. Vincent J, Lekha NC. Bio-Engineered Copper Oxide Nanoparticles Using Citrus Aurantifolia Enzyme Extract and its Anticancer Activity. Journal of Cluster Science. 2020 Nov 17:1-9.

28. Wang Y, Li Y, Zhang Y, Wei W. Enhanced brilliant blue FCF adsorption using microwave-hydrothermal synthesized hydroxyapatite nanoparticles. Journal of Dispersion Science and Technology. 2019 Jun 4.

29. Yallappa S, Manjanna J, Dhananjaya BL. Phytosynthesis of stable Au, Ag and Au-Ag alloy nanoparticles using $\mathrm{J}$. sambac leaves extract, and their enhanced antimicrobial activity in presence of organic antimicrobials. SpectrochimicaActa Part A: Molecular and Biomolecular Spectroscopy. 2015 Feb 25;137:236-43. 
30. Yamani HA, Pang EC, Mantri N, Deighton MA. Antimicrobial activity of Tulsi (Ocimumtenuiflorum) essential oil and their major constituents against three species of bacteria. Frontiers in microbiology. 2016 May 17;7:681.

\section{Figures}

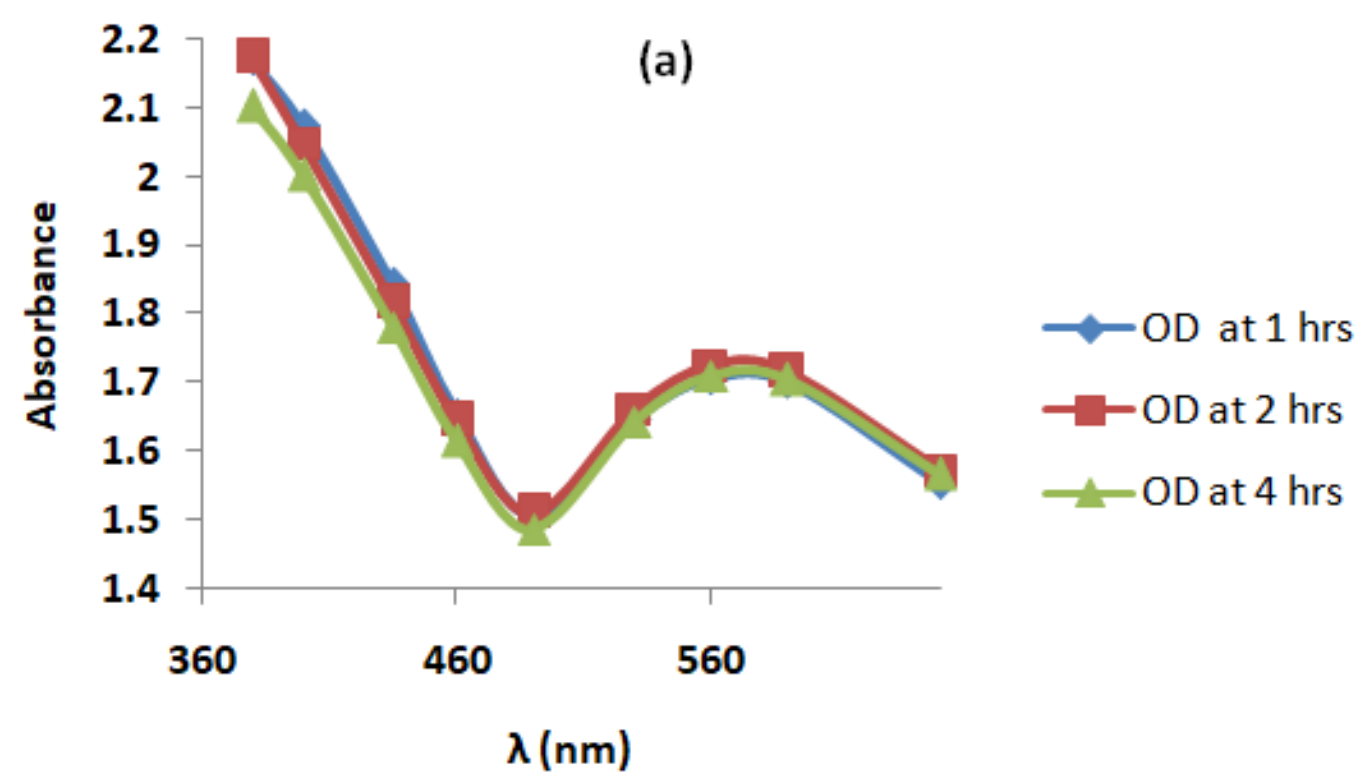

(b)

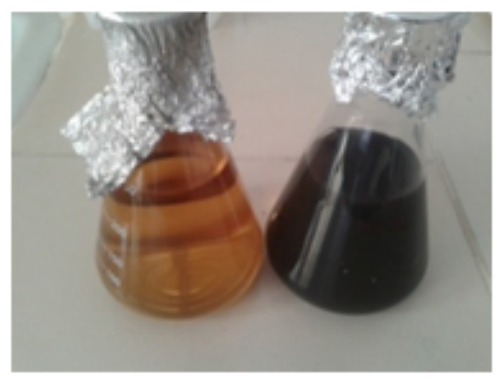

Figure 1

(a) UV-Visible spectrums of OTAuAgNPs, (b) Visual confirmation of OTAuAgNPs synthes 


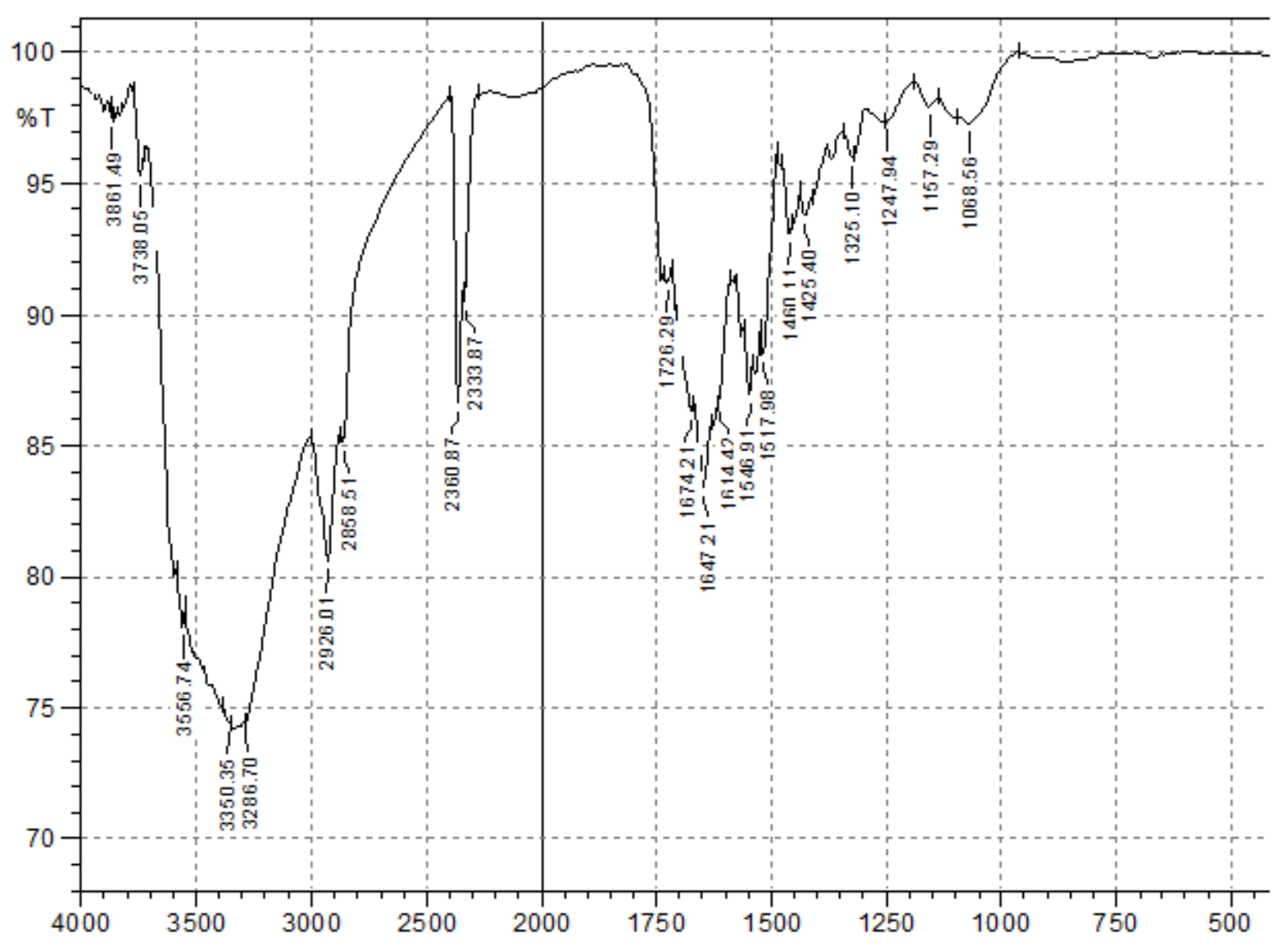

Figure 2

FT-IR of Ocimumtenuiflorumle afextract 


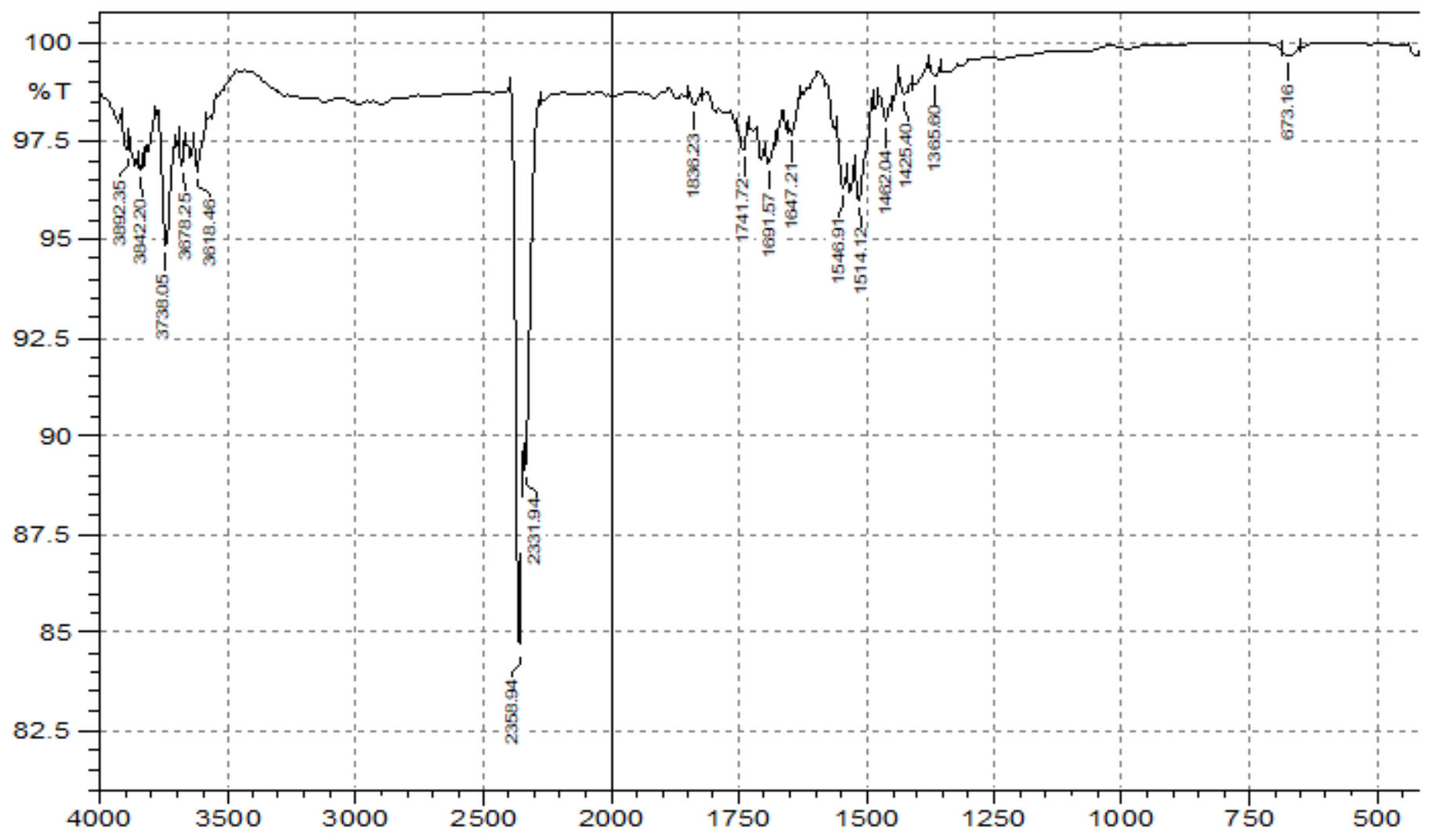

Figure 3

FT-IR of OTAuAgNPs
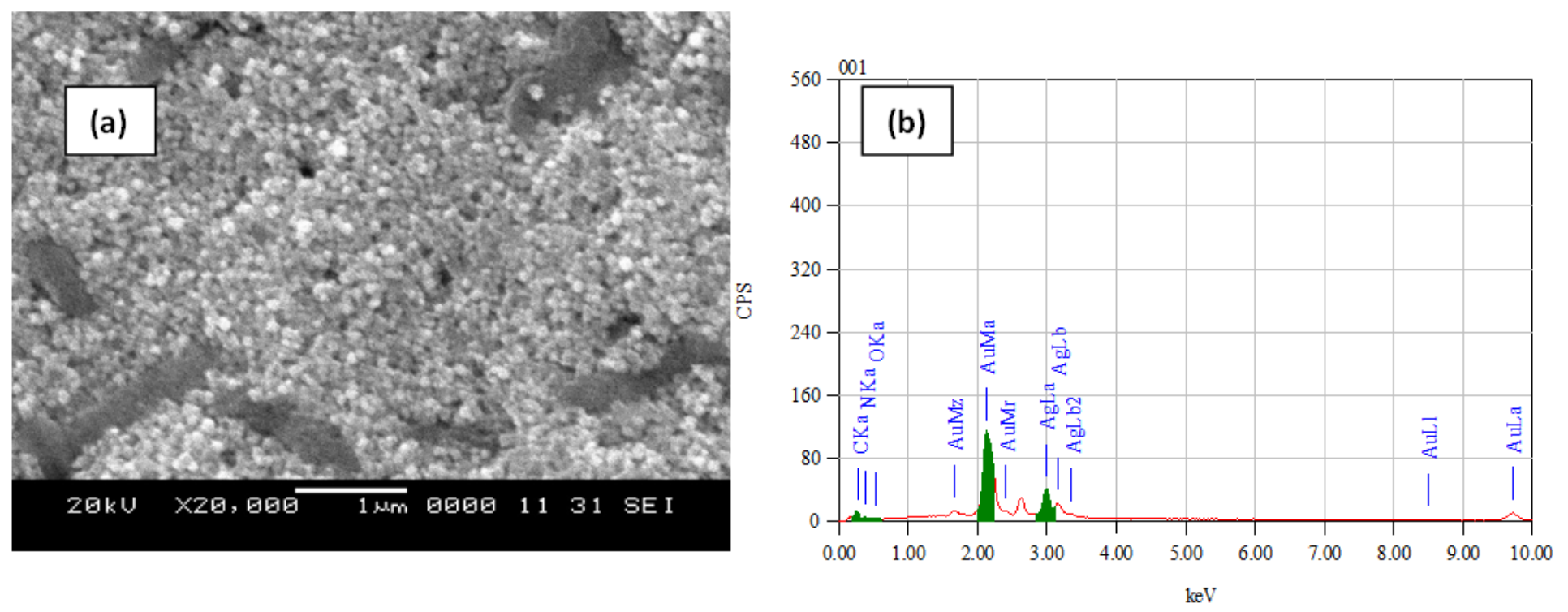

Figure 4

(a)FESEM and (b) EDAX of OTAuAgNPs showing its morphology and composition 
Size Distribution by Intensity

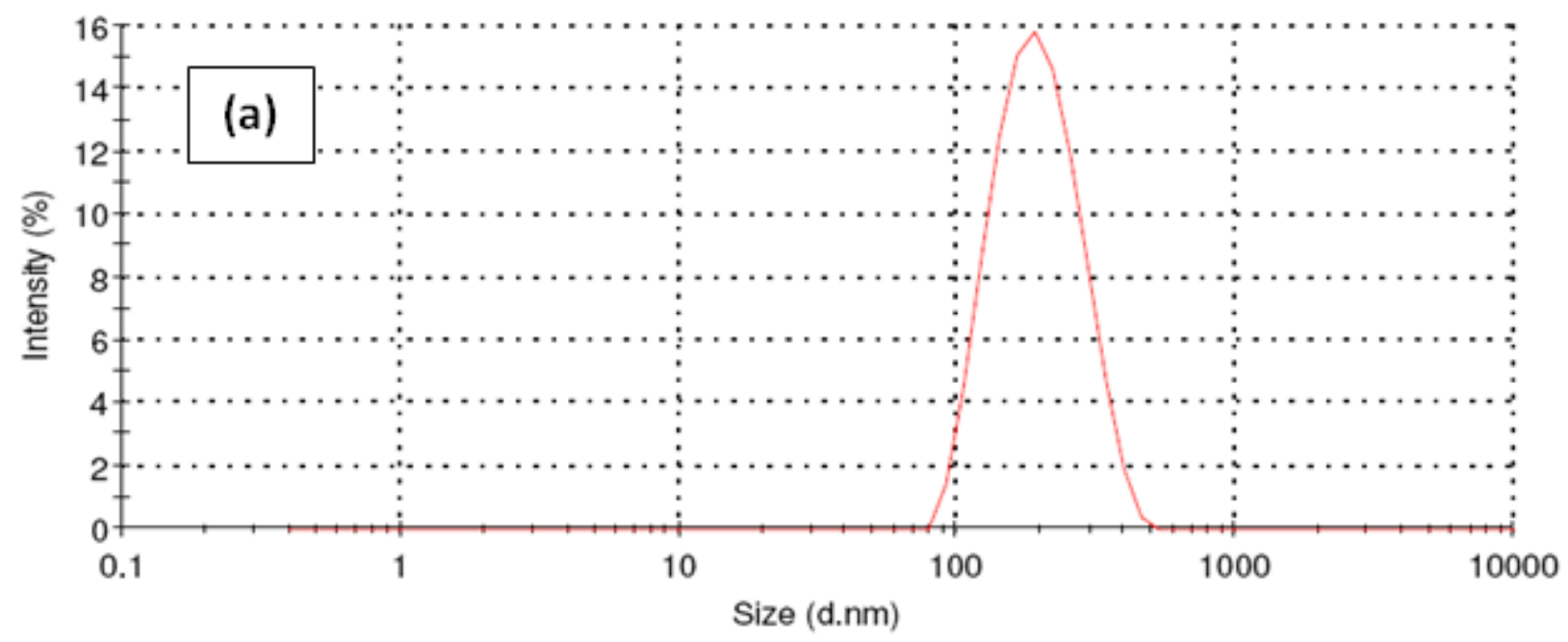

Zeta Potential Distribution

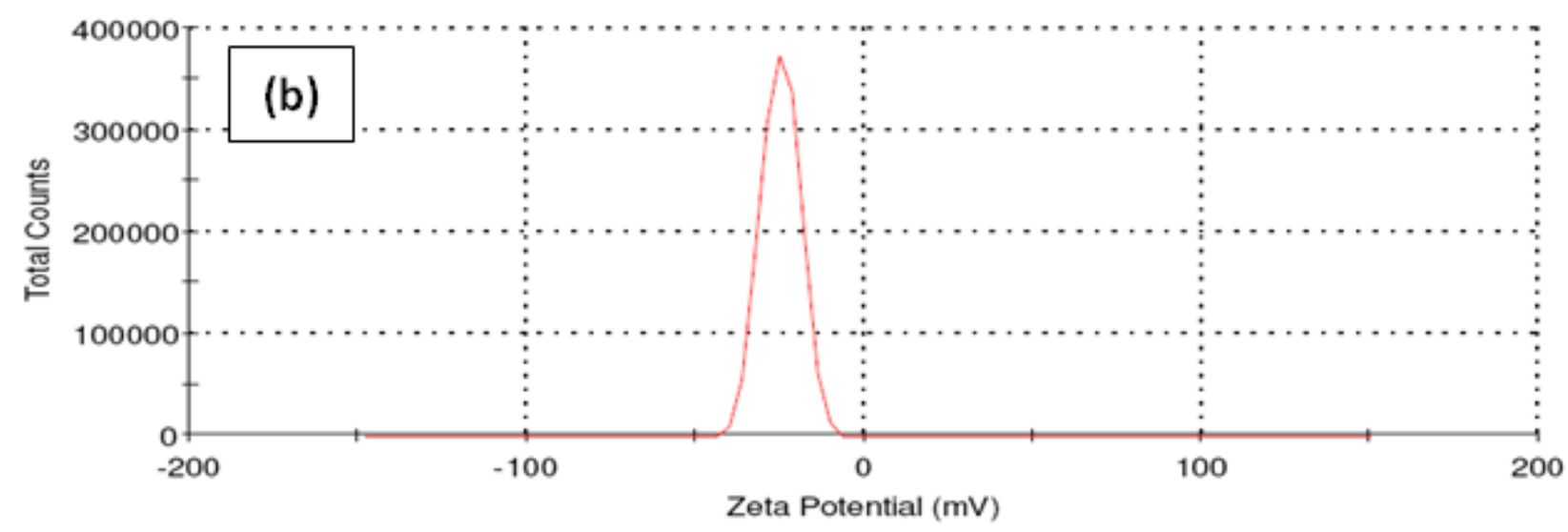

Figure 5

(a) Particle size distribution and (b) Zeta analysis of bimetallic OTAuAgNPs 


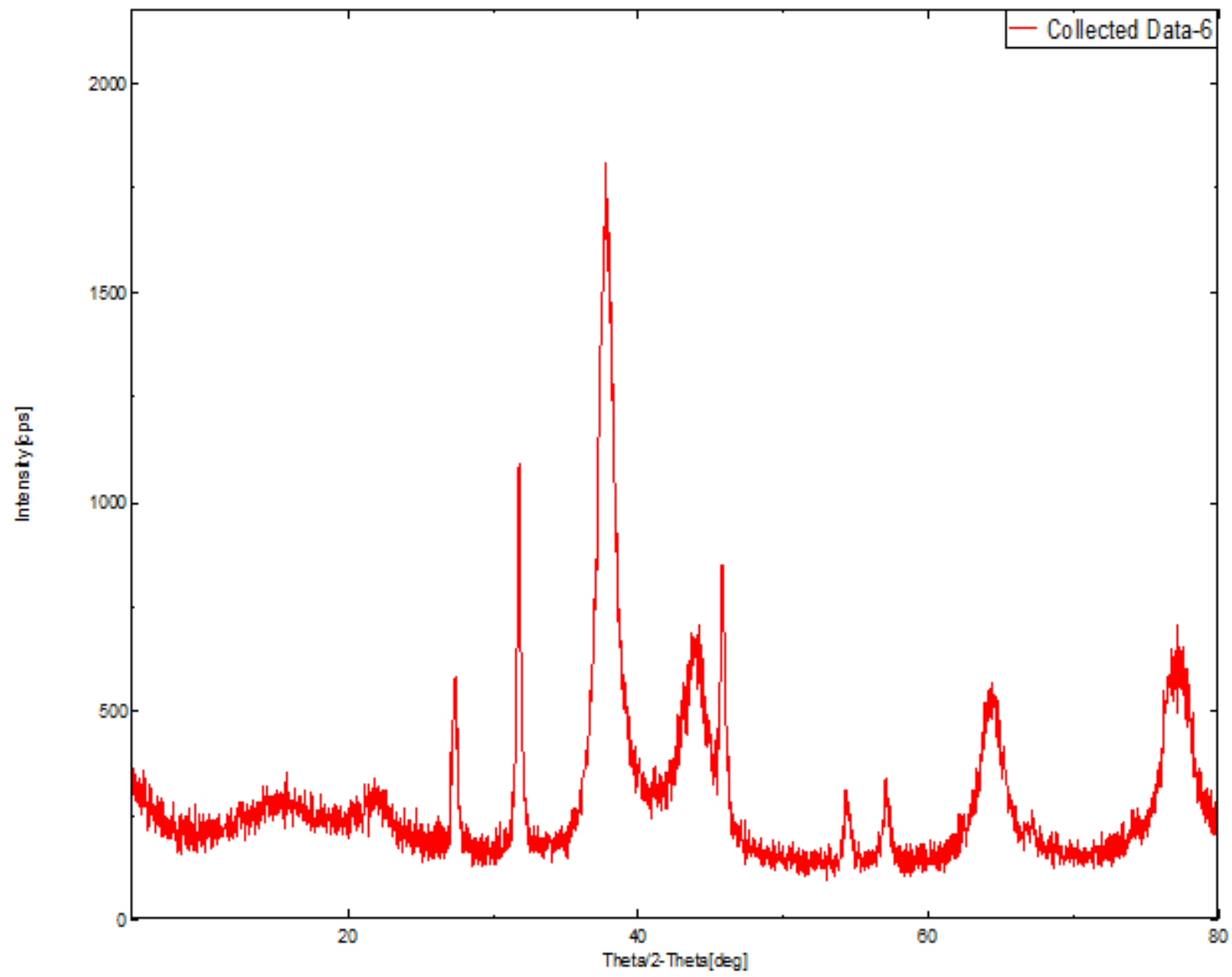

Figure 6

XRD pattern of OTAuAgNPs 

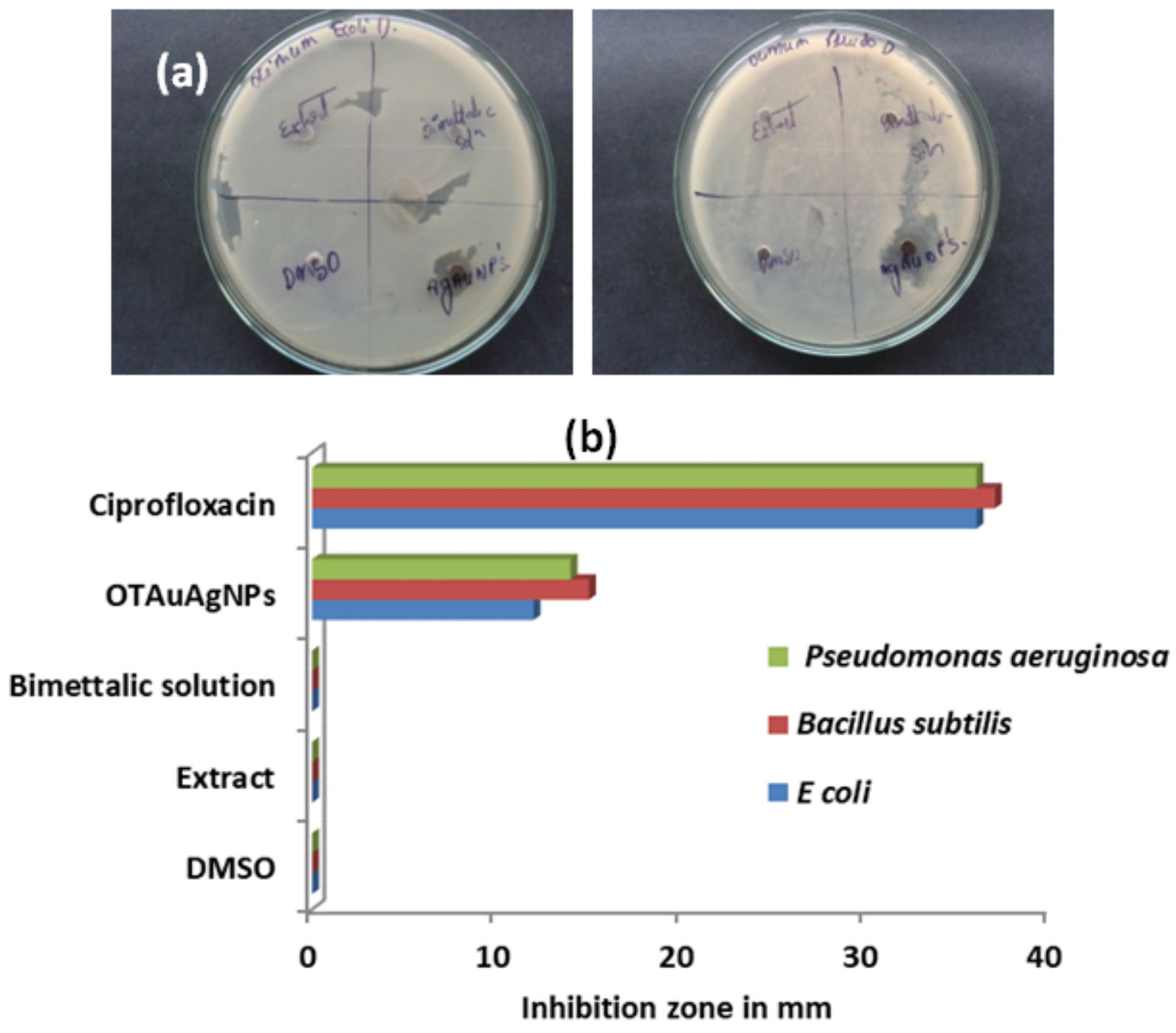

Figure 7

Bactericidal activity of OTAuAgNPsagainst the test organisms (A) Sample petriplates of E.coliand Pseudomomas aeruginosa showing the inhibition zone(B) Bar graph showing the antibacterial results for all the samples. 


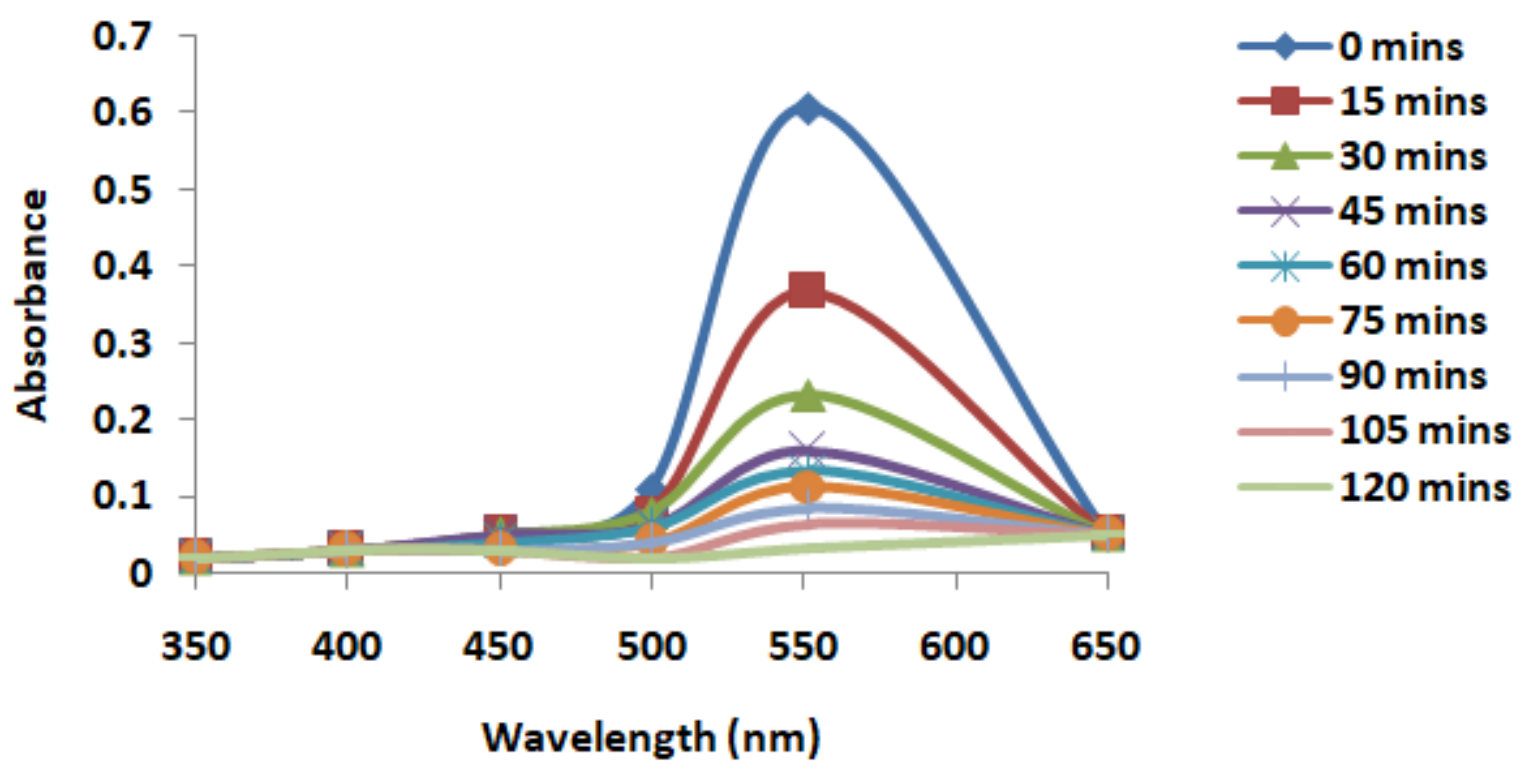

Figure 8

CBB dye absorption by OTAuAgNPs
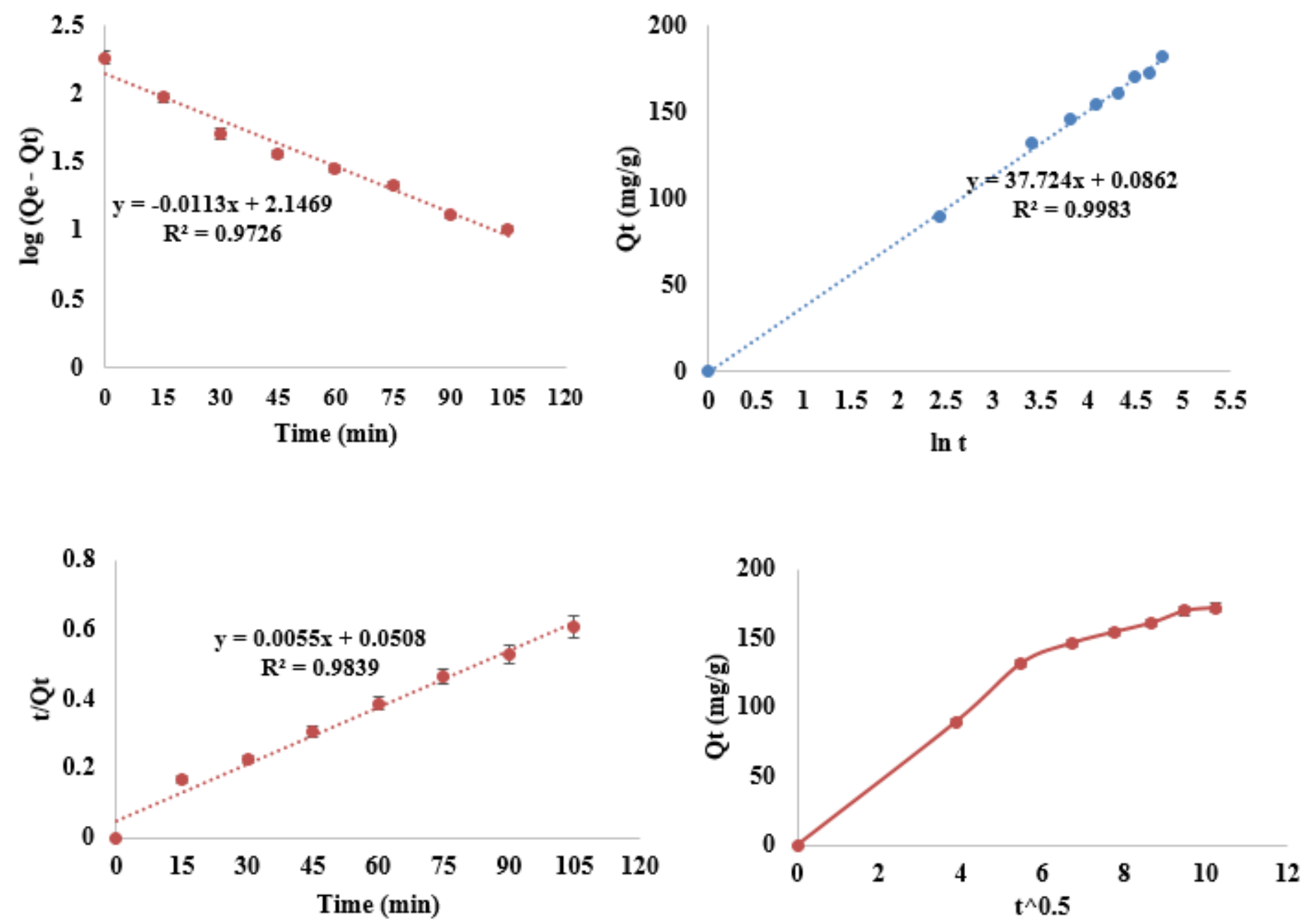


\section{Figure 9}

PSO (A), PFO (B), Elovich (C) and intraparticular diffusion (D) models depicting the adsorption kinetics of CBB by synthesized OTAuAgNPs

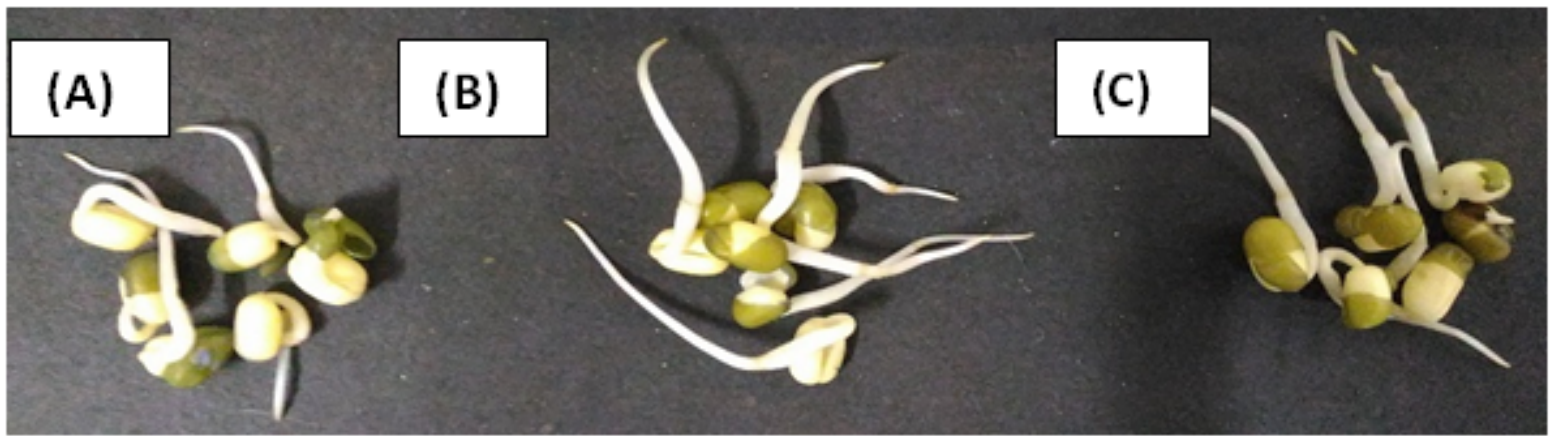

Figure 10

Effect of (A) CBB, (B) MCBB and (C) Water on the seed germination of Vignaradiata

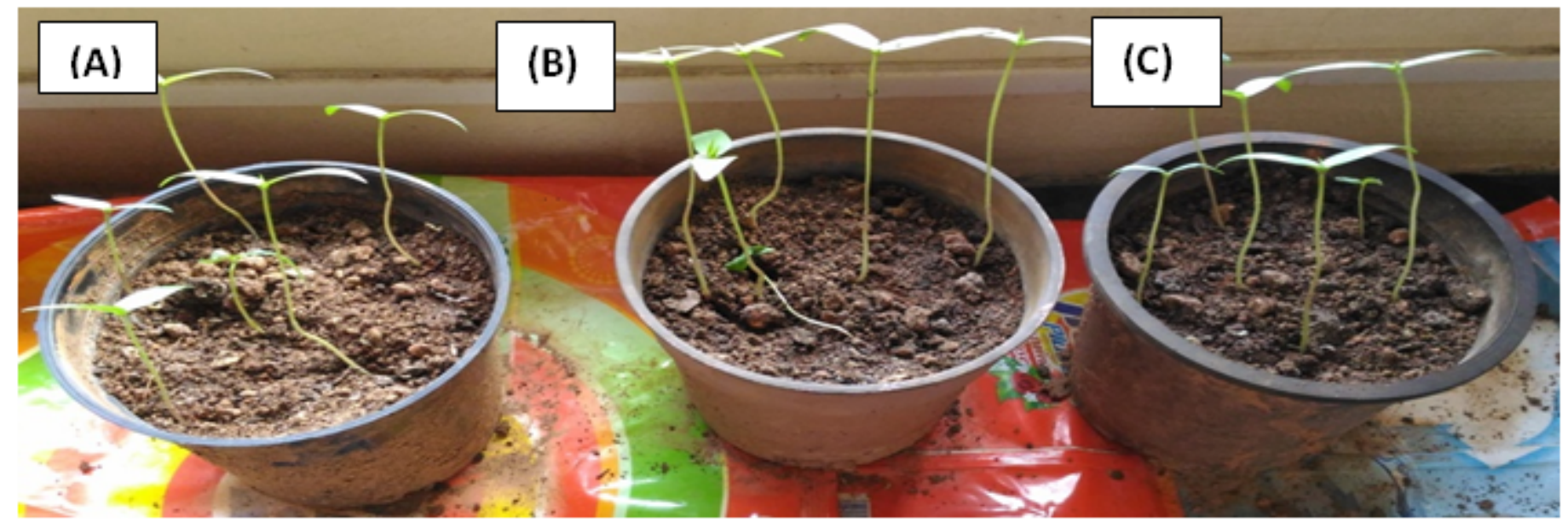

\section{Figure 11}

Effect of (A) CBB, (B) MCBB and (C) Water on Vignaradiata seedlings after it underwent 5 days of germination 